\title{
Online medical consultation: covid-19 system using software object-oriented approach
}

\author{
Ali Yahya Gheni ${ }^{1}$, Hiba Adil Yousif ${ }^{2}$, Yusmadi Yah Jusoh $^{3}$ \\ ${ }^{1,2}$ Department of Computer Science, University of Baghdad, Iraq \\ ${ }^{3}$ Department of Software Engineering and Information System, Universiti Putra Malaysia (UPM), Malaysia
}

\section{Article Info \\ Article history: \\ Received Jul 18, 2021 \\ Revised Sep 29, 2021 \\ Accepted Oct 24, 2021}

\section{Keywords:}

Covid-19 pandemic

Expert review

Object-oriented

Online medical consultation

Usability test

\begin{abstract}
The internet has been a source of medical information, it has been used for online medical consultation (OMC). OMC is now offered by many providers internationally with diverse models and features. In OMC, consultations and treatments are available 24/7. The covid-19 pandemic across-the-board, many people unable to go to hospital or clinic because the spread of the virus. This paper tried to answer two research questions. The first one on how the OMC can help the patients during covid-19 pandemic. A literature review was conducted to answer the first research question. The second one on how to develop system in OMC related to covid-19 pandemic. The system was developed by Visual Studio 2019 using software object-oriented approach. Online expert review was conducted within 6 experts from health and academic industry to verify the model. Also, the system was validated by 11 users from heath and academic industry to confirm its usability. The statistical package for social science (SPSS 22) was used to analyze the collected data. The result of expert review confirmed that covid-19 system can help the patients. Also, the validity of the system was confirmed by 11 users from health and academic industry.
\end{abstract}

This is an open access article under the CC BY-SA license.

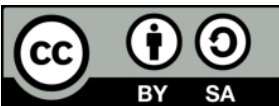

\section{Corresponding Author:}

Ali Yahya Gheni

Department of Computer Science

College of Education for Pure Science/Ibn Al-Haitham

University of Baghdad, Iraq

Email: ali.y.g@ihcoedu.uobaghdad.edu.iq

\section{INTRODUCTION}

Many people make their own medical decision by using the internet as a source of health-related information [1], [2]. The term "online medical consultation" (OMC) is used in this research to refer to medical consultations conducted via the internet. The phrase "remote consultation" refers to "consultation via remote telecommunications, often for the purpose of diagnosis or treatment," therefore OMC can be considered part of telemedicine. In three major ways, however, this paper distinguishes OMC from remote consultations. For starters, non-internet-based consultations such as phone-only or radio-based consultations are not included in the definition of OMC. Second, OMC represents a paradigm shift in the way patients seek medical advice, allowing them to "shop around" for medical advice in the same way they shop for other online services. Third, while OMC focuses on direct patient-doctor consultations, it excludes doctor-doctor (provider-provider) consultations as well as consultations for health education and other objectives. The notion of OMC goes beyond traditional telemedicine, which is usually limited to specific medical categories for patients in specific geographical/geopolitical zones. Patients with a wide range of medical needs from various locations or nations are usually welcome to use OMC. Patients have the option of selecting or being allocated to any doctor or care provider who is available online. They are not constrained to a single provider 
based on prior experience or proximity to them. Many countries throughout the world are becoming more reliant on OMC in their health systems as a result of the covid-19 pandemic outbreak.

Individual medical decisions are increasingly being made using the internet as a source of healthrelated information [3], [4]. The majority of publications evaluated remote consultation utilization for a single medical practice rather than a big group. Medical consequences, communication methods, and information exchange were the key topics of discussion. Consumer demographics, ailment categories, reaction times, and certain effect and financial factors were all investigated in various OMC research [5]-[7].

OMC services are said to be popular among customers. Researchers from Pittsburgh University in the United States found that the eVisit services provided patients with benefits in terms of access, speed, and convenience while reducing the risk of improper or incomplete care [8].

There are no globally agreed definitions for the nomenclature used to designate various medical services supplied via the internet [9]. Teleconsultation [10], [11], e-Visit [12], [13], e-Consultation [14], [15], video consultation [16]-[18], or online medical consultation [19]-[23] are some of the terms used to describe internet consultations. The term eVisit is more commonly used in the United States. In many sources, however, the name is connected with the asynchronous variant of OMC [24].

OMC provides a wealth of research and practice options. Since the turn of the century, OMC has piqued the interest of both suppliers and customers. Healthcare consumers have always wanted to be able to communicate with doctors-electronically-the way they do with the rest of the world, according to the editor of Health Management Technology magazine in 2006 [25]. This is especially true for non-urgent matters that do not require a face-to-face office visit.

Recent study [26] supports a similar point. Patients from outlying areas, the elderly and disabled, and those suffering from chronic ailments are likely to flock to OMC. Young and internet-savvy persons, as well as those with rigid working conditions, may prefer it. According to academic assessments of telemedicine/OMC/eVisits, patients benefit from enhanced convenience and accessibility to health services, less travel and waiting time to visit a doctor, and a more cost-effective delivery option [27].

Patients don't have to leave their homes or places of work, sit in traffic, then sit in a room with other patients, perhaps catch or cause an infection in the process, and then return home. A baby's mother may not need to accompany her child to a clinic for diagnosis of a basic disease like diaper rash, which doctors may diagnose accurately from certain photos. Patients with chronic conditions may benefit from OMC since it allows them to undertake routine checkups and obtain test results without having to visit a clinic unless they specifically request it.

Patients ranging in age from 4 days (for diaper rash) to 86 years (for sleeplessness and hypertension) used the Mayo Clinic eVisit pilot program's online consultation service in 2010 [28]. OMC is a potential new technology. eVisits have been demonstrated to be practical with excellent patient satisfaction scores in several US papers [29].

Concerns have also been made about the safety and quality of OMC practices. According to a study conducted in Australia, just $29 \%$ of the study group (young people) were willing to participate in a video consultation about their sexual health difficulties, while 63 percent preferred telephone consultation [30]. Despite its international success, telepsychiatry has a limited penetration in Australia, according to another study [31]. According to a recent media release from the royal Australian college of general practitioners (RACGP), certain OMC providers' service delivery model makes it more difficult for doctors to diagnose patients without fully understanding the medical and social context or being able to perform a physical examination [32].

Furthermore, OMC's economic benefits may be questioned. The use of online GP consultations has been demonstrated to increase the cost of healthcare in Denmark [33]. Another study in the United Kingdom found a lack of evidence in teledental applications in terms of cost-effectiveness, quality, efficacy, and patient satisfaction [34]. The following is how the paper is structured: The first section is an introduction, which includes the OMC-related work as documented in the literature. The research technique and process are presented in section 2, the system development is presented in section 3, and the results and discussions are explored in section 4 . Section 5 concludes with a summary of the findings and recommendations for future research.

\section{RESEARCH METHOD}

This paper's initial study question is: How might the OMC assist patients? To answer the first research question, a literature study was conducted:

RQ1: How can the OMC assist patients in the event of a covid-19 pandemic?

RQ2: How to establish system in OMC for covid-19 pandemic is the second research question.

Visual Studio 2019 was used to create the system, which used a software object-oriented strategy.

Bulletin of Electr Eng \& Inf, Vol. 10, No. 6, December 2021 : 3471 - 3480 
To verify the model, six professionals from the health and academic industries participated in an online expert review. The system's usability was also confirmed by 11 users from the health and academic industries.

\subsection{Confirmation study/expert review}

To verify the model, it was subjected to an expert review by six specialists ( 3 from the health business and 3 from academia). According to [35], the minimal number of expert reviews is three. Two experts were handed a draft of the expert evaluation (the first one in the English language and the second in questionnaire form). The expert evaluation was carried out, and the outcome was analyzed. The model was fine-tuned in response to expert feedback. Figure 1 shows the process of confirmation study.

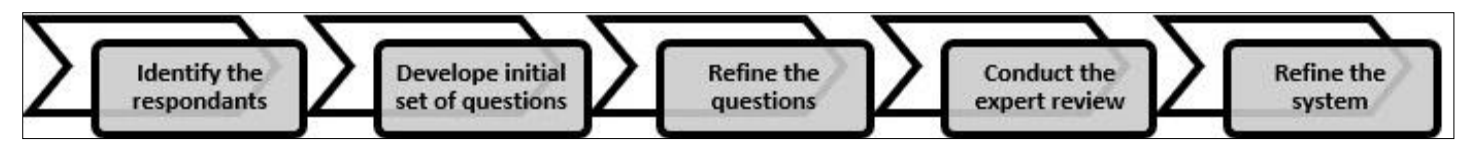

Figure 1. The process of confirmation study /expert review

\subsection{Confirmation study/survey (usability test)}

The technology was put to the test in two locations, each in a different industry. In Iraq, the top spot goes to a hospital in the health business, while the second place goes to a university in the academic industry. The snowball sampling technique was used to select a sample from these two industries at random. The system usability scale (SUS) questionnaire was given to 11 respondents (5 from the health business and 6 from the academic industry) [36]. The questionnaires, which were adapted from [37] and initially from [38], asked respondents about the system's ease of use when doing certain tasks. The questionnaires' subjective usability assessment is based on a Likert scale. The tool uses a five-point Likert-type rating scale (ranging from "strongly disagree" to "strongly agree") with 10 questions about satisfaction, efficiency, and effectiveness to measure the usability of the system.

\section{SYSTEM DEVELOPMENT}

We developed this system by Visual Studio 2019 using object-oriented approach. In the objectoriented approach, the focus is on capturing the structure and behavior of information systems into small modules that combines both data and process. The main aim of object-oriented design (OOD) is to improve the quality and productivity of system analysis and design by making it more usable. The main components of the covid-19 system that will affect the interaction between covid-19 system and its users are:

- System log in: The user should log in with the right username and password which is mentioned by the system otherwise, wrong message will appear.

- $\quad$ Start the test:

- $\quad$ The user should enter the current temperature.

- $\quad$ The user should choose Yes or No from the symptoms in the system.

- $\quad$ Treatment course for 7 days: The system offered course of treatment for 7 days, this course is offered by World Health Organization.

- Some instructions on how to protect yourself: The system presents some important instructions to keep the user safe.

- Questions and answers related to covid-19 pendamic: The system give the opportunity to the patient to ask questions and the system will give the answer.

- $\quad$ Contact number: The user can call to get instructions a live from doctors and for emergency case.

\subsection{Use case diagram}

A use case diagram is a system analysis tool for identifying and organizing system requirements [39]. All system actions that are important to users are represented in the use case diagram. A use case is a collection of possible interactions between systems and users in a certain compound that are tied to a specific purpose. The use case is used to identify system users and their actions in the system; it is also used to explicitly explain the link between the functions of each user, such as which functions should be performed and which are optional. The covid-19 system's requirements are supplemented by the use case diagram, which depicts the system's user and functions. Figure 2 depicts a use case diagram. Identify covid-19 system users and all of the covid-19 system functions they perform [40], [41]. 


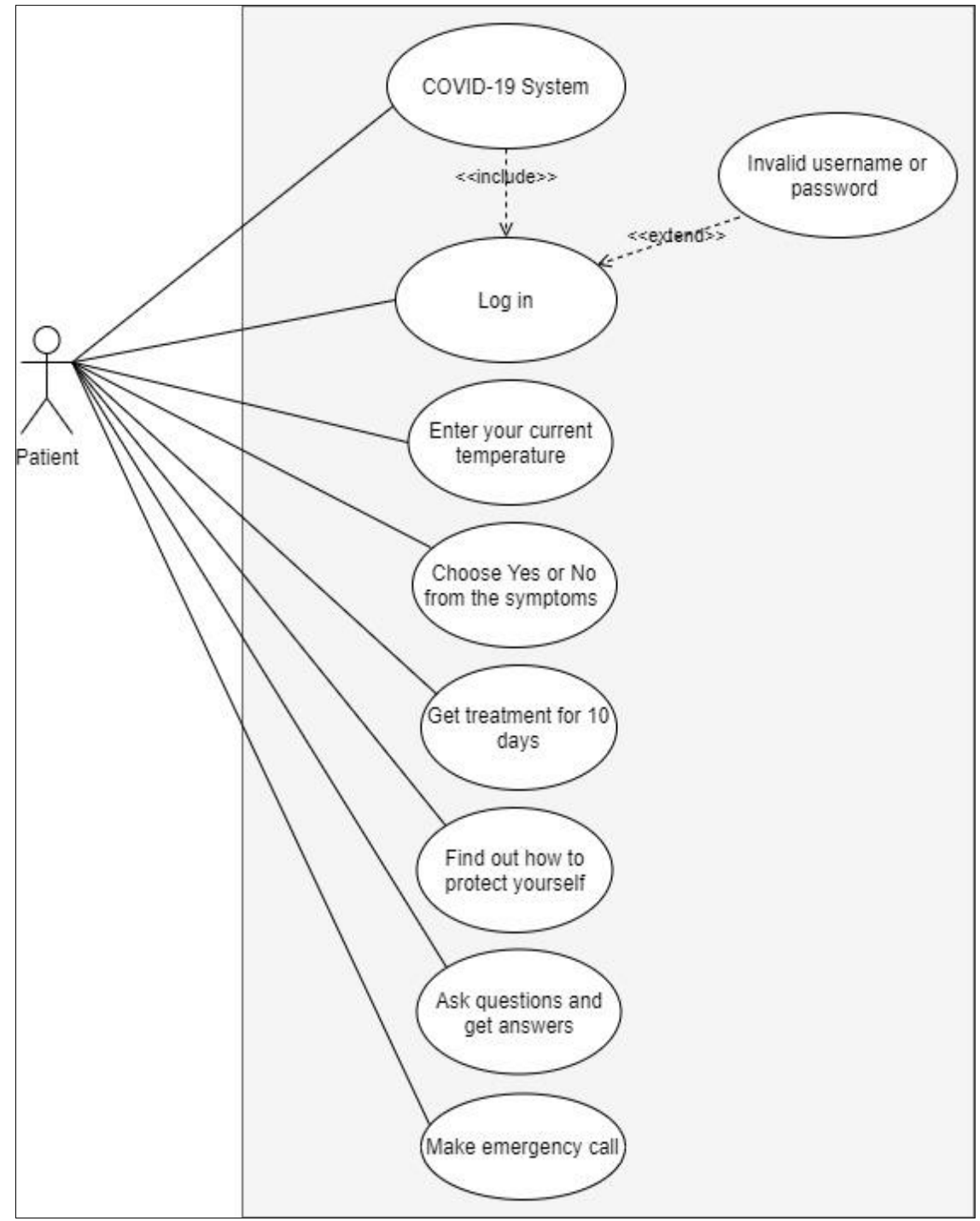

Figure 2. Covid-19 system use case diagram

\subsection{System activity diagram}

The workflow behavior of the covid-19 system was described using activity diagrams. Because activities are the state of doing something in the system, activity diagrams are similar to state diagrams. It's also used to represent the covid-19 system's workflow and is beneficial for analyzing use cases by stating what activities must be taken. In the preceding sections, the requirements of the covid-19 system and its users were identified. Activity diagrams were used to examine the covid-19 system's use case through each of the system's functions. So, as shown in Figure 3, the general activity of the covid-19 system begins with requests from the user to insert the username and password; after entering the correct username and password, the user can smoothly log in to the covid-19 system, after which the user can enter the temperature, symptoms, and so on. Figure 3 shows the system activity diagram.

\subsection{System inplementation}

The OMC is available in a number of shapes and designs, and the GUI design chosen and executed was determined by the analysis and design processes. And, in order to provide better support, the system was handed to numerous users for a test drive in order to obtain input on accessibility testing. The users must input the correct username and password on the login screen, as shown in Figure 4. Covid-19 is a buttonbased system that may be used by a wide range of users. Figure 5 depicts the screen. Figure 6 depicts the notion of object-oreiented, which is dominant, and the rest of the author's code for the covid-19 system. 


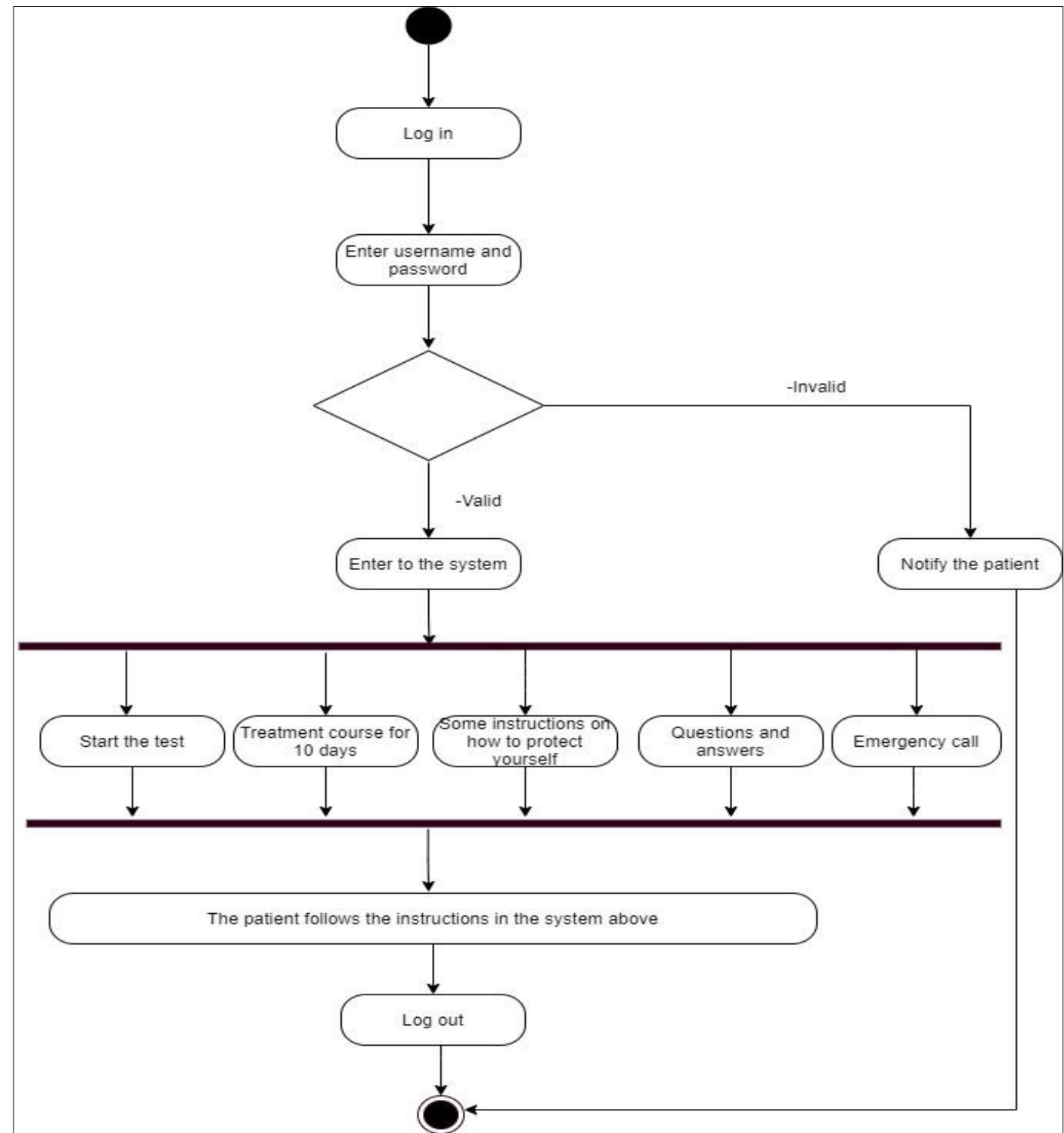

Figure 3. Covid-19 system activity diagram

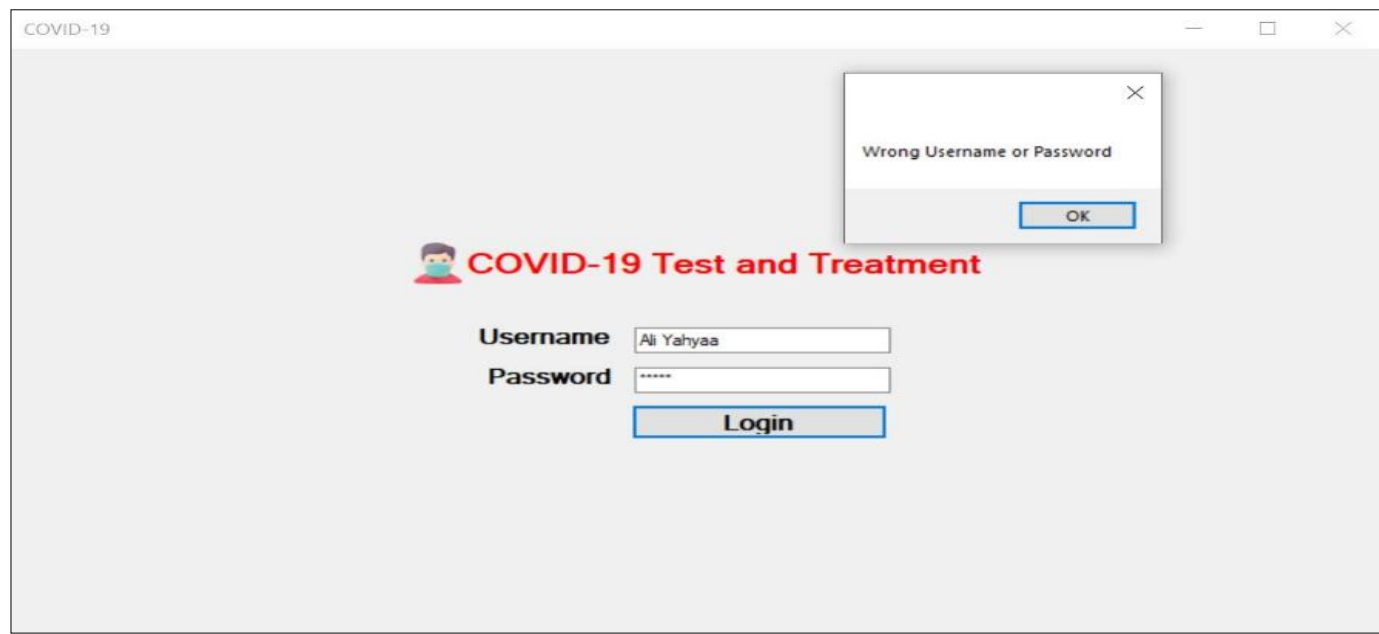

Figure 4. Covid-19 system log in 


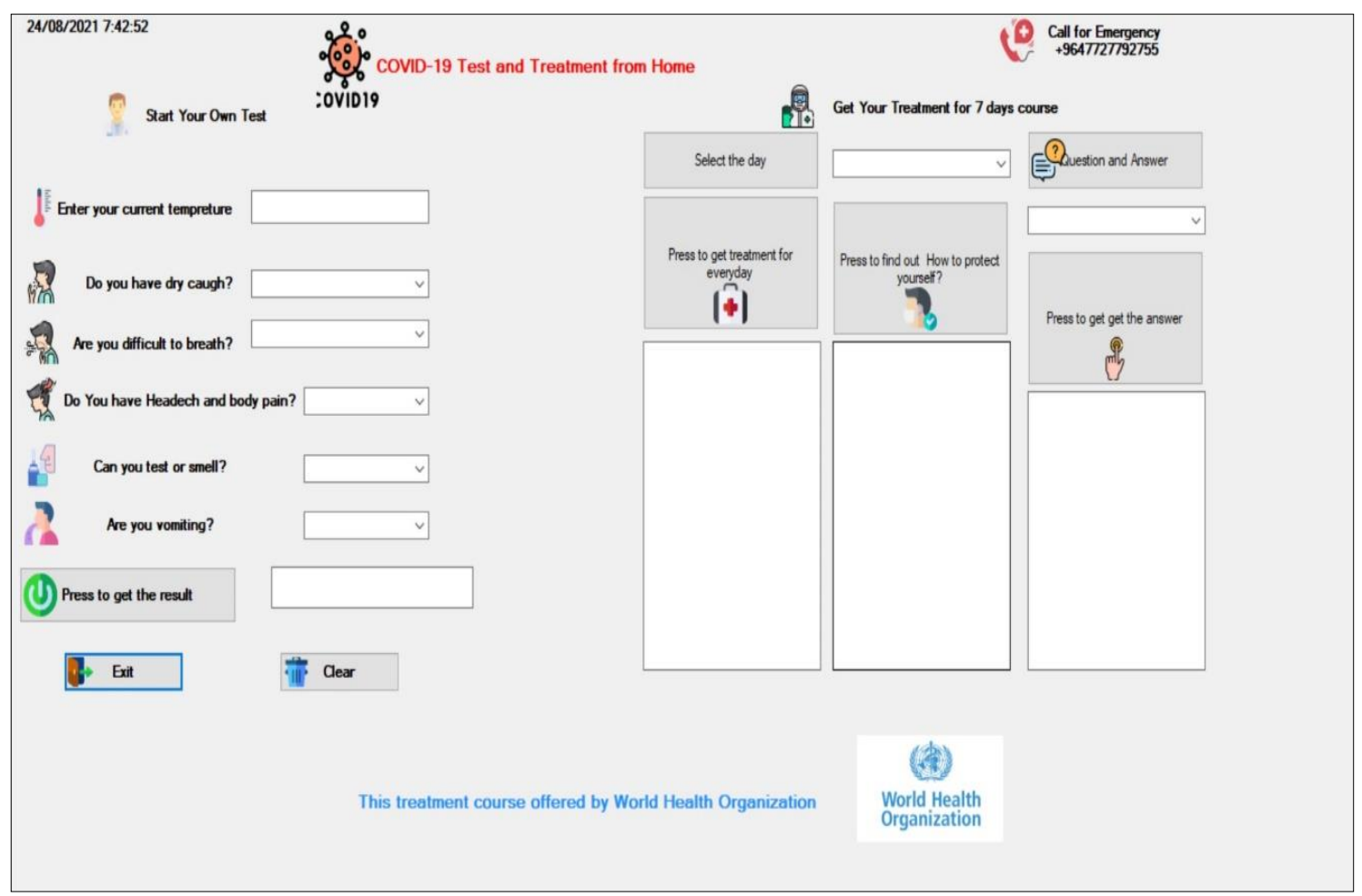

Figure 5. Covid-19 system interface

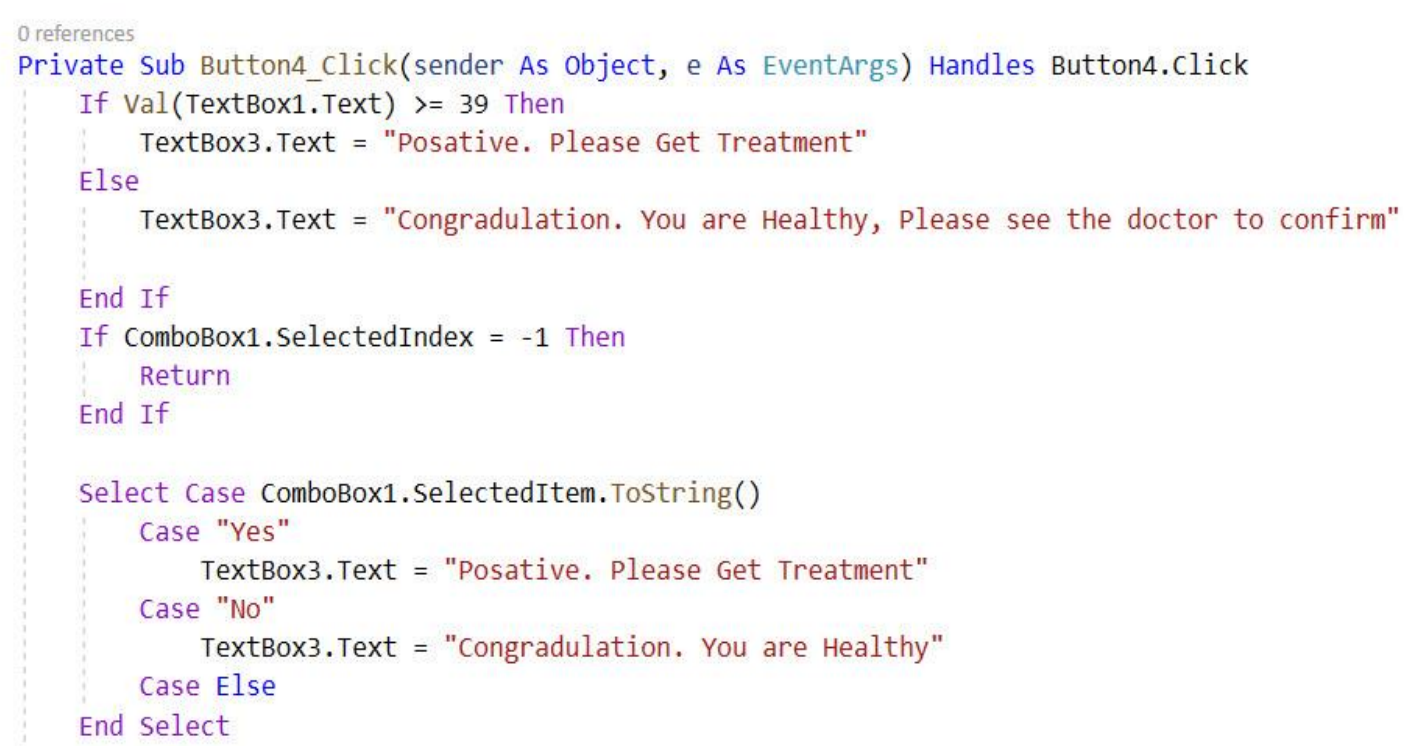

Figure 6. Sample of covid-19 system code

\section{RESULTS AND DISCUSSION}

\subsection{Results of confirmation study/expert review}

After sending the draft of an expert questionnaire interview to one expert in English language and one in questionnaire design, the questionnaire was refined, and the results were analyzed after an expert review with six experts ( 3 from the health industry and another three from the academic industry). The findings suggest that experts believe that the proposed paradigm is feasible. The experts also agree on the suggested model's applicability, comprehensiveness, understandability, accuracy, and coherence. 


\subsection{Results of confirmation study/survey (usability test)}

After removing the damaged case and examining the outliers, the final sample consisted of 45.5 percent males and 54.5 percent females. 17.3 percent of those who responded were between the ages of 26 and 35. The Middle East was represented by all of the respondents. Because the study's focus was on hospitals and universities, 45.5 percent of respondents worked in the medical field, while 54.5 percent worked in academia. 63.6 percent of the samples have job experience ranging from 11 to 15 years. Finally, all of them are from the public sector. Table 1 provides more detailed information on the demographic characteristics of respondents.

\begin{tabular}{|c|c|c|}
\hline No & + & Percent \\
\hline \multirow[t]{3}{*}{1} & Gender & \\
\hline & Female & $54.5 \%$ \\
\hline & Male & $45.5 \%$ \\
\hline \multirow[t]{6}{*}{2} & Age & \\
\hline & Less than 26 & \\
\hline & $26-35$ & $17.3 \%$ \\
\hline & $36-45$ & $9.1 \%$ \\
\hline & $46-55$ & $63.6 \%$ \\
\hline & More than 55 & \\
\hline \multirow[t]{6}{*}{3} & Nationality & \\
\hline & Asian & \\
\hline & Middle East & $100 \%$ \\
\hline & European & \\
\hline & North America & \\
\hline & South America & \\
\hline \multirow[t]{3}{*}{4} & Industry & \\
\hline & Academic & $54.5 \%$ \\
\hline & Health & $45.5 \%$ \\
\hline \multirow[t]{4}{*}{5} & Qualification & \\
\hline & Doctors & $18.3 \%$ \\
\hline & Academic & $76.7 \%$ \\
\hline & Software developer & \\
\hline \multirow[t]{7}{*}{6} & Work experience & \\
\hline & Less than one year & \\
\hline & $1-5$ years & $18.2 \%$ \\
\hline & $6-10$ years & $18.2 \%$ \\
\hline & $11-15$ years & $63.6 \%$ \\
\hline & $16-20$ & $18.2 \%$ \\
\hline & More than 20 years & \\
\hline \multirow[t]{3}{*}{7} & Organization type & \\
\hline & Government & \\
\hline & Semi government & $100 \%$ \\
\hline
\end{tabular}

The technology was put through its paces in one hospital and one university. Several employees from these two companies were chosen utilizing the snowball sampling technique. An online survey was sent to 11 people ( 5 from the health business and 6 from the academic industry). Table 2 shows how the results were analyzed using SPSS 22.

According to Table 2, the majority of respondents strongly agree that the system is simple to use and understand. 81.8 percent of users stated they would like to use the system frequently in response to item 1 ("I believe I would like to use this system frequently"). 81.8 percent of respondents strongly agree with item 2 ("I considered the system unnecessarily complex"). However, because this is a negative item ("I believe I would require the assistance of a technical expert to be able to use this system"), users' responses to "strongly disagree" (81.8 percent) and "disagree" (18.2 percent) are high. "Strongly disagree" (81.8 percent) and "disagree" ( 81.8 percent) were similarly used by respondents for question 6 ("I thought there was too much inconsistency in this system") (18.2 percent).

In addition, replies to item 8 ("I found the system onerous to use") reveal that users viewed the system to be simple and straightforward. Item 10 demonstrates how simple the system is to learn. Finally, the findings of the ten elements relating to system usability indicate that the system's usability is high, and users are highly satisfied. 
Table 2. Frequency distribution for responses related to usability

\begin{tabular}{|c|c|c|c|c|c|}
\hline no & Item & Strongly Disagree & Disagree & Agree & Strongly Agree \\
\hline 1 & I think that I would like to use this system frequently. & & & $18.2 \%$ & $81.8 \%$ \\
\hline 2 & I found the system unnecessarily complex. & & & $18.2 \%$ & $81.8 \%$ \\
\hline 3 & I thought the system would be easy to use. & & & $18.2 \%$ & $81.8 \%$ \\
\hline 4 & $\begin{array}{l}\text { I think that I would need the support of a technical person to } \\
\text { be able to use this system. }\end{array}$ & $81.8 \%$ & $18.2 \%$ & & \\
\hline 5 & I found the various functions in this system well integrated. & & & $9.1 \%$ & $90.9 \%$ \\
\hline 6 & I thought there was too much inconsistency in this system. & $81.8 \%$ & $18.2 \%$ & & \\
\hline 7 & $\begin{array}{l}\text { I would imagine that most people would learn to use this } \\
\text { system quickly. }\end{array}$ & & & $9.1 \%$ & $90.9 \%$ \\
\hline 8 & I found the system cumbersome to use. & $81.8 \%$ & $18.2 \%$ & & \\
\hline 9 & I felt confident using the system. & $9.1 \%$ & $90.9 \%$ & & \\
\hline 10 & $\begin{array}{l}\text { I needed to learn a lot of things before I could get going with } \\
\text { this system. }\end{array}$ & $9.1 \%$ & $90.9 \%$ & & \\
\hline
\end{tabular}

\section{CONCLUSION}

In conclusion, literature review was conducted to highlighted the importance of OMC for all patients around the world. Furthermore, covid-19 system was developed to help the patients to do their own test and get treatment for those who are affected. Different instructions mentioned in this system to keep everyone safe and healthy. Finally, further research needs to do to develop OMC models of services and care.

\section{ACKNOWLEDGEMENTS}

First, I we would like to express our sincere gratitude to University of Baghdad for the continuous support of the research in our academic environment. Secondly many thanks to Universit Putra Malaysia (UPM) for all the knowledge we gain during our PhD and research journey.

\section{REFERENCES}

[1] S. H. Kessler and S. S.-Weitmann, "Diseases and emotions: An automated content analysis of health narratives in inquiries to an online health consultation service," Health Communication, vol. 36, no. 2, pp. 226-235, 2021, doi: 10.1080/10410236.2019.1673950.

[2] F. Yang, L. Yu, D. Qin, F. Hua and G. Song, "Online consultation and emergency management in paediatric dentistry during the COVID-19 epidemic in Wuhan: A retrospective study," International journal of paediatric dentistry, vol. 31, no. 1, pp. 5-11, 2021, doi: 10.1111/ipd.12722.

[3] F. Eurobarometer, "European citizens' digital health literacy," A report to the European Commission, 2014.

[4] L. He and E. Smit. "Vague Language in Online Medical Consultation: An Experimental Study of Uncertainty and Its Consequences," European Journal of Health Communication, vol. 2, no. 1, pp. 1-28, 2021, doi: 10.47368/ejhc.2021.001.

[5] R. Padman, G. Shevchik, S. Paone, C. Dolezal and J. Cervenak, "eVisit: a pilot study of a new kind of healthcare delivery," MEDINFO, pp. 262-266, 2010, doi: 10.3233/978-1-60750-588-4-262.

[6] A. Mehrotra, S. Paone, G. D. Martich, S. M. Albert and G. J. Shevchik, "Characteristics of patients who seek care via eVisits instead of office visits," Telemedicine and e-Health, vol. 19, no. 7, pp. 515-519, 2013, doi: 10.1089/tmj.2012.0221.

[7] S. C. Adamson and J. W. Bachman, "Pilot study of providing online care in a primary care setting," in Mayo Clinic Proceedings, vol. 85, no. 8, pp. 704-710, 2010, doi: 10.4065/mcp.2010.0145.

[8] S. M. Albert, G. J. Shevchik, S. Paone and G. D. Martich, "Internet-based medical visit and diagnosis for common medical problems: experience of first user cohort," Telemedicine and e-Health, vol. 17, no. 4, pp. 304-308, 2011, doi: 10.1089/tmj.2010.0156.

[9] W. Zhao, C. Wang and Y. Nakahira. "Medical application on internet of things," in IET international conference on communication technology and application (ICCTA 2011), pp. 660-665, 2011.

[10] B. Joseph, G. Hadeed, M. Sadoun, P. M. Rhee and R. S. Weinstein, "Video consultation for trauma and emergency surgical patients," Critical care nursing quarterly, vol. 35, no. 4, pp. 341-345, 2012, doi: 10.1097/CNQ.0b013e318266c2f2.

[11] K. Deldar, P. Marouzi and R. Assadi, "Teleconsultation via the web: an analysis of the type of questions that Iranian patients ask," Journal of telemedicine and telecare, vol. 17, no. 6, pp. 324-327, 2011, doi: $10.1258 /$ jtt.2011.101206.

[12] R. Bhargava, G. Gayre, J. Huang, E. Sievers and M. Reed, "Patient e-Visit Use and Outcomes for Common Symptoms in an Integrated Health Care Delivery System," JAMA Network Open, vol. 4, no. 3, pp. e212174e212174, 2021, doi: 10.1001/jamanetworkopen.2021.2174.

[13] N. Gidwani, L. Fernandez and D. Schlossman, "Connecting with patients online: E-visits," US Dept. Family Commun. Med. Academic Health Center, Techinacal Report, 2012. 
[14] E. Keely, C. Liddy and A. Afkham, "Utilization, benefits and impact of an e-consultation service across diverse specialties and primary care providers," Telemedicine and e-Health, vol. 19, no. 10, pp. 733-738, 2013, doi: 10.1089/tmj.2013.0007.

[15] S. LS Drop, P. Mure, D. Wood, A. El-Ghoneimi and S. Faisal Ahmed, "E-consultation for DSD: a global platform for access to expert advice," Journal of pediatric urology, vol. 8, no. 6, pp. 629-632, 2016, doi: 10.1016/j.jpurol.2012.10.009.

[16] M. Jiwa and X. Meng, "Video consultation use by Australian general practitioners: video vignette study," Journal of medical Internet research, vol. 15, no. 6, p. e117, 2013, doi: 10.2196/jmir.2638.

[17] C. Liddy, M. S. Rowan, A. Afkham, J. Maranger and E. Keely, "Building access to specialist care through econsultation," Open Medicine, vol. 7, no. 1, pp. e1, 2013, doi: 10.2478/S11536-011-0121-2.

[18] A. C. Smith, N. R. Armfield, J. Croll and L. C. Gray, "A review of Medicare expenditure in Australia for psychiatric consultations delivered in person and via videoconference," Journal of telemedicine and telecare, vol. 18, no. 3, pp. 169-171, 2012, doi: 10.1258/jtt.2012.SFT111.

[19] T. Herawati, H. Herwastoeti and M. Isrok, "Online Health Consultation Services In Indonesia Law Perspective," in Proceedings of the 3rd International Conference on Indonesian Legal Studies, ICILS 2020, July 1st 2020, Semarang, Indonesia, 2021, doi: 10.4108/eai.1-7-2020.2303667.

[20] R. A. Bailey, "The legal, financial and ethical implications of online medical consultations," J. Tech. L. \& Pol'y, vol. 16, pp. 53, 2011.

[21] C. Brockes, J. S. Schenkel, R. N. Buehler, K. Grätz and S. Schmidt-Weitmann, "Medical online consultation service regarding maxillofacial surgery," Journal of Cranio-Maxillofacial Surgery, vol. 40, no. 7, pp. 626-630, 2012, doi: 10.1016/j.jcms.2012.03.018.

[22] H. Lu, B. R. Shaw and D. H. Gustafson, "Online health consultation: Examining uses of an interactive cancer communication tool by low-income women with breast cancer," International journal of medical informatics, vol. 80, no. 7, pp. 518-528, 2011, doi: 10.1016/j.ijmedinf.2011.03.011.

[23] Y. Zhang, "How doctors do things with empathy in online medical consultations in China: A discourse-analytic approach," Health communication, vol. 36, no. 7, pp. 816-82, 2021, doi: 10.1080/10410236.2020.1712527.

[24] G. J. Joyia, R. M. Liaqat, A. Farooq and S. Rehman, "Internet of medical things (IoMT): Applications, benefits and future challenges in healthcare domain," J. Commun, vol. 12, no. 4, pp. 240-247, 2017.

[25] R. Blair, "Phone-free virtual visits. Aetna covers online doctor-patient communication for insured members in Florida and California," Health management technology, vol. 27, no. 7, pp. 24-26, 2006.

[26] R. A. Dudas and M. Crocetti, "Pediatric caregiver attitudes toward email communication: survey in an urban primary care setting," Journal of medical Internet research, vol. 15, no. 10, p. e2738, 2013, doi: 10.2196/jmir.2738.

[27] J. Moffatt and D. S. Eley, "Barriers to the up-take of telemedicine in Australia-a view from providers," Rural Remote Health, vol. 11, no. 2, p. 1581, 2011, doi: 10.22605/RRH1581.

[28] S. C. Adamson and J. W. Bachman, "Pilot study of providing online care in a primary care setting," in Mayo Clinic Proceedings, vol. 85, no. 8, pp. 704-710, 2010, doi: 10.4065/mcp.2010.0145.

[29] I. Al-Mahdi, K. Gray and R. Lederman, "Online Medical Consultation: A review of literature and practice," in Proceedings of the 8th Australasian workshop on health informatics and knowledge management, pp. 27-30, 2015.

[30] C. C. Garrett, J. Hocking, M. Y. Chen, C. K. Fairley and M. Kirkman, "Young people's views on the potential use of telemedicine consultations for sexual health: results of a national survey," BMC Infectious Diseases, vol. 11, no. 1, pp. 1-11, 2011, doi: 10.1186/1471-2334-11-285.

[31] C. S. Anthony, N. R. Armfield, J. Croll and L. C. Gray, "A review of Medicare expenditure in Australia for psychiatric consultations delivered in person and via videoconference," Journal of telemedicine and telecare, vol. 18, no. 3, pp. 169-171, 2012, doi: 10.1258/jtt.2012.SFT111.

[32] D. Matyushina and I. Kalabikhina, "A study of the population's attitude to telemedicine technologies on the example of online medical consultations," Population and Economics, vol. 2, no. 2, p. 78-109, 2018, doi: 10.3897/popecon.2.e36048.

[33] R. Medaglia and K. Normann Andersen, "Information systems and healthcare XXXVIII: Virus outbreak- Online GP consultations escalating healthcare costs," Communications of the Association for Information Systems, vol. 27, no. 1, pp. 711-724, 2010

[34] R. N. Patel and G. S. Antonaraki, "Factors influencing the adoption and implementation of teledentistry in the UK, with a focus on orthodontics," Community dentistry and oral epidemiology, vol. 41, no. 5, pp. 424-431, 2013, doi: $10.1111 /$ cdoe. 12029 .

[35] N. A. M. Asarani and N. Z. Ab Rahim, "Preliminary study of online training implementation from multiple perspectives in malaysian public sectors," Journal of Theoretical and Applied Information Technology, vol. 90, no. 1, p.77, 2016.

[36] W. Albert and T. Tullis, "Measuring the user experience: collecting, analyzing, and presenting usability metrics," Newnes, 2013.

[37] N. Harrati, I. Bouchrika, A. Tari and A. Ladjailia, "Exploring user satisfaction for e-learning systems via usagebased metrics and system usability scale analysis," Computers in Human Behavior, vol. 61, pp. 463-471, 2016, doi: 10.1016/j.chb.2016.03.051.

[38] J. Brooke, "SUS-A quick and dirty usability scale," Usability evaluation in industry, vol. 189, no. 194, pp. 4-7, 1996.

[39] K. Lano, "Advanced systems design with Java, UML and MDA," Elsevier, 2005, doi: 10.1016/B978-0-7506-64967.X5000-7. 
[40] A. Gemino and D. Parker, "Use case diagrams in support of use case modeling: Deriving understanding from the picture," Journal of Database Management (JDM), vol. 20, no. 1, pp. 1-24, 2009, doi: 10.4018/jdm.2009010101.

[41] M. Ryhage, "Volatility forecasting performance: An evaluation of GARCH-class models," Amadeus Wennström, 2021.

\section{BIOGRAPHIES OF AUTHORS}
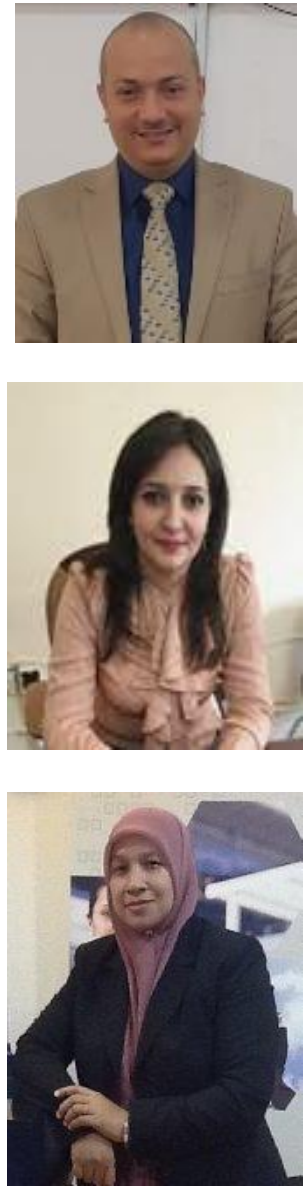

Ali Yahya Gheni, he holds his PhD from Universiti Putra Malaysia (UPM) in Information Systems, Faculty of Computer Science and Information Technology, Department of Software Engineering and Information Systems, Malaysia. He holds his MSc. from University College of Technology and Innovation (UCTI) in Information Technology Management, Department of Information Technology Management, Malaysia. He holds his BSc. in Computer Science from University of Baghdad, Department of Computer Science, Iraq. He is currently worked as a senior lecturer in University of Baghdad, Department of Co. Science. His research interest includes Information Systems, Information Technology Management and Software Engineering.

Hiba Adel Yousif holds her MSc. from Universiti Putra Malaysia (UPM) in Software Engineering, Faculty of Computer Science and Information Technology, Department of Software Engineering and Information Systems, Malaysia. She holds his BSc. in Computer Science from University of Baghdad, Department of Computer Science, Iraq. She is currently work as a lecturer in University of Baghdad, Department of Co. Science. Her research interest includes Software Engineering and Information Systems.

Yusmadi Yah Jusoh received the Ph.D. degree in System Science and Management from the National University of Malaysia (UKM) in 2008. Currently, she is an Associate Professor at Universiti Putra Malaysia (UPM), Faculty of Computer Science and Information Technology. Her research interest is in Management Information System, Information System, Information Technology Strategic Planning, and Software Project Management. Yusmadi is also a certified software tester and an academician at Department of Software Engineering and Information System, Faculty of Computer Science, and Information Technology, UPM since 1998. In 2008 she received her $\mathrm{PhD}$ in System Science and Management from UKM. She teaches software project management, team software project management, information systems, and management information systems. Her research interest includes software project management, information systems, performance measurement, and management information system. 